Southern Methodist University

SMU Scholar

\title{
Energy Market and Policy Revolutions: Regulatory Process and the Cost of Capital
}

James W. Coleman

Southern Methodist University, Dedman School of Law

\section{Recommended Citation}

James W. Coleman, Energy Market and Policy Revolutions: Regulatory Process and the Cost of Capital, Energy Law and Economics (Klaus Mathis \& Bruce Huber, eds) (Springer, 2018)

This document is brought to you for free and open access by the Faculty Scholarship at SMU Scholar. It has been accepted for inclusion in Faculty Journal Articles and Book Chapters by an authorized administrator of SMU Scholar. For more information, please visit http://digitalrepository.smu.edu. 


\title{
Energy Market and Policy Revolutions: Regulatory Process and the Cost of Capital
}

\author{
James W. Coleman
}

\begin{abstract}
As the world embarks on a transition toward a low-carbon economy, one common characteristic of alternatives to fossil fuels has gone surprisingly unexamined: the cost of these alternative sources is disproportionately concentrated in capital expenses, rather than operating expenses. Solar, wind, and hydro power have very low operating expenses: the cost of these power sources is largely in their construction. Even nuclear power has low fuel costs compared to fossil fuel power sources. So as the world decarbonizes the power grid and electrifies the transportation sector, capital costs will grow increasingly important in the energy sector. At the same time, several trends in energy law have been conspiring to raise the cost of capital. First, privatization and deregulation of electric utilities mean that energy investors are less certain of recovering their capital investments. Second, a push for more public participation in decision-making on energy infrastructure has, at times, resulted in delays and uncertainty that make private companies even more wary of long-term capital investments in new energy facilities. Third, the drive for more careful and holistic environmental assessments of new energy facilities has, in some cases, further delayed new infrastructure, again making private investors wary of large, new investments. This Article considers how to manage these conflicting trends, describing how governments can achieve public participation and improved environmental assessment while, at the same time, ensuring the predictability that can support capital investment in a new energy economy. It also explores particular areas where these tensions may be irreconcilable, suggesting ways that governments may be able to serve the goals of expanded participation and assessment, while providing private capital with traction to achieve a transition away from fossil fuels.
\end{abstract}

\section{Introduction: Attracting Capital to Build the New Energy Economy}

The world is facing two monumental challenges that are in tension: maintaining broad-based economic growth while, at the same time, decarbonizing the world economy to meet global climate goals. To meet these challenges, the world will need to attract massive investment in new sources of power to expand electricity access in developing countries and replace coal power fleets in the world's major economies. The International Energy Agency predicts that this task will require 
more than two trillion dollars of new investment. ${ }^{1}$ Achieving these twin goals is made more difficult by another emerging tension in energy investment: low carbon energy investments are increasingly capital-intensive but, at the same time, several developments in energy law are making returns on investment more uncertain, raising the cost of capital.

The United States Clean Power Plan (Plan) - the first attempt to control greenhouse gas emissions from the existing power sector in the world's largest economy - demonstrates how low carbon polies will require major capital investments. The Plan, currently on hold because of the U.S. Supreme Court and the incoming Trump administration, envisioned replacing the U.S. coal fleet with a mix of increased power from solar and wind and natural gas power. ${ }^{2}$ Despite the massive environmental downsides of coal power, it minimizes capital costs: it is easy and cheap to transport to the places it is needed and to store where it is needed, which are major challenges for both natural gas and renewable power. In the run up to the Plan, in November 2014, the U.S. electric power reliability watchdog, the North American Electric Reliability Corporation warned that the Plan would endanger the reliability of electric service unless it was accompanied by a massive build out of gas and electricity transport and storage. ${ }^{3}$

The electricity system must constantly match electricity supplied with electricity demanded. Solar and wind power, however, cannot be dispatched on demand-they are produced only when the sun shines or the wind blows and thus far we do not have ways to economically store electric power until it is needed. Natural gas can back up solar and wind, but it is a gas, which makes it expensive to transport and store. Power is also expensive to transport and store, so a transition from coal to renewables and natural gas would require expensive investments in both gas and power transport and storage.

At the same time that this need for new transport infrastructure is building, there is increased uncertainty attached to energy investment around the world. First, privatization and deregulation of electric utilities has meant that less and less of power sector investment by companies is made based on a guaranteed rate of return through a regulatory compact. Second, increasing interest and activism focused on

\footnotetext{
${ }^{1}$ International Energy Agency 2014.

2 The Supreme Court prevented the Plan from taking effect, West Virginia v. Envtl. Prot. Agency, 136 S. Ct. 1000, 1000 (2016), and thus far the courts have, at the request of the Trump administration, agreed to keep the Plan in limbo while the administration works to repeal it. Timothy Cama, Court suspends case over Obama climate rule, The Hill, April 28, 2017, http://hehill.com/policy/energy-environment/331060-court-suspends-case-over-obama-climate-rule.

${ }^{3}$ North American Electric Reliability Corporation 2014.
} 
energy infrastructure has, at times, resulted in delays and uncertainty that made private companies even more wary of long-term capital investments. Third, a trend toward more wide-ranging environmental assessments of new energy facilitiesembodied in the Keystone XL precedent and its application to facilities across the world, as explained in Section 3 of this chapter- has further delayed new infrastructure, again making private investors wary of large, new investments. Together these three trends are raising the cost of capital for investing in new energy infrastructure, and thus raising the cost of achieving the world's environmental goals.

This Article proceeds in four further parts. Section 2 describes why ongoing revolutions in energy markets and policy call for massive new capital investments in low carbon power production and transport. Section 3 describes how trends in energy law and policy are, at the same time, increasing the uncertainty and cost of long-term investment in the energy industry. Section 4 evaluates possible methods of encouraging more investment in the industry while accommodating the policy concerns that are resulting in increased delay and uncertainty for energy investors. Section 5 concludes.

\section{Transitioning to a Low Carbon Economy Will Require Massive Long-term Energy Investment}

As mentioned above, the transition to a low carbon economy requires massive capital investment in the energy system. Renewable power must be not only built but, potentially even more challenging, carried to centres of power demand by new power transmission. A natural gas boom will complement expanded renewable power better than coal, but it will require more pipelines to carry it to market and more storage to ensure that it is available when non-dispatchable wind and solar power fails. And to move transportation and other sectors away from oil, the economy will require more electricity and a more flexible electrical distribution grid.

Renewable sources such as wind and utility-scale solar power are easiest to site in low-population density areas, which are often also the deserts and plains where these resources are richest. That power must be transmitted to the urban centres of electricity demand. This in turn requires multi-billion dollar investments in longdistance power transmission.

At the same time, transitioning to a low carbon economy will require closing coal plants. So until electricity storage becomes widely available and affordable, increased natural gas power will be required as a replacement to back up renewable sources that only provide power when the sun shines and the wind blows. And natural gas is a better complement for renewable power sources because it can easily 
be ramped up and down to balance solar and wind sources-offering little power when the sun is shining and the wind is blowing but providing a lot of power when those sources fail and consumers demand power. ${ }^{4}$

But one persistent advantage of coal has been its ease of transport and storage. In much of the industrialized world towns grew up near coal mines and rivers that could transport coal and the existing railroad infrastructure was, in large part, designed to facilitate movement of coal to centres of electricity demand.

By contrast, gas will require much more expensive infrastructure to ensure that the precise amount of gas is constantly being delivered to exactly the places that it is needed to accommodate spikes in electricity demand or dips in renewable power supply. As a gas, it is more expensive to transport: long haul, air-tight pipelines are multi-million dollar projects, liquefaction facilities to bring gas to overseas markets cost tens of millions, and even the liquefied natural gas ships that shuttle between these facilities cost a quarter of a billion dollars each. ${ }^{5}$

Storing gas also requires major capital investments. Coal can simply be stored in piles, but to store natural gas, a company must find an air-tight aquifer, depleted reservoir, or salt cavern that can hold the gas until it is needed. The difficulty of finding suitable storage locations was dramatically illustrated in 2016 when the Southern California Gas Company overfilled a storage reservoir at Aliso Canyon, creating a major leak that took four months to plug and forced thousands of citizens to abandon their homes. ${ }^{6}$

As the world's carbon reduction goals grow more ambitious, the need for capital investment will simply grow more pressing. For now, countries and regions that pursue climate regulation often limit their costs by relying on countries with lower ambitions for carbon regulation. For example, they can purchase emission reductions from foreign countries where they are cheap because those nations have not yet pursued inexpensive low-hanging-fruit reductions. ${ }^{7}$ Or they can import lowerprice electricity or commodities from these less-ambitious countries. ${ }^{8}$ But as climate targets grow stronger across the world, countries will increasingly be forced to actually close fossil-fuel plants and connect to new sources of renewable power that will often be far away. And they will be forced to build out electricity and natural

\footnotetext{
${ }^{4}$ Coleman 2017a.

${ }^{5}$ U.S. Department of Energy 2015.

${ }^{6}$ U.S. Energy Info. Admin. 2016.

${ }^{7}$ Coleman 2014b.

${ }^{8} I d$.
} 
gas storage to ensure that their grid remains reliable at high penetrations of renewable power. ${ }^{9}$

Even further investments in power transmission infrastructure may be one important strategy to increase the reliability of intermittent sources like wind and solar power. If a regional grid can diversify the geographic area powering its renewable sources, they may provide more reliable power. Even if the sun is not shining in one region, it may be shining in a neighbouring state or country. ${ }^{10}$

Finally, the most difficult stage in decarbonization-moving away from oilwill require further capital investments. Oil is the most energy dense fossil fuel and it is easy to move because, as a liquid, it can be pumped by pipeline or be easily placed on ships, trucks, or rail cars. As we try to electrify our transport system we will need to expand power generation to accommodate this new demand and expand power transport to make sure that quick charging stations are widely available to support a flexible transportation network.

\section{Energy Law Trends Are Raising Uncertainty for Energy Investors and Increasing the Cost of Building the Energy Future}

At the same time, other trends in energy law are conspiring to raise uncertainty for energy investors. The transmission to competitive markets has meant that fewer investors can be certain that their energy investments will receive a steady stream of income that justifies the initial capital investment. At the same time, increased public focus on energy infrastructure has repeatedly delayed energy infrastructure projects, increasing the risk that a project will never even be completed. Finally, expanded environmental assessments have raised new hurdles to constructing new energy transport facilities.

The most significant trend of the past thirty years in energy law is restructuring - creating competition in markets through a combination of breaking down vertically-integrated utilities and more surgical rate regulation of energy transport bottlenecks that could otherwise exercise monopoly power. ${ }^{11}$ In many of the

\footnotetext{
${ }^{9}$ The most plausible alternatives to a major build out in renewable power, such as nuclear power and carbon capture, would also require massive capital investment. Woite, 1978; Rao, 2007.

${ }^{10}$ Roques 2010.

${ }^{11}$ Sioshani 2006.
} 
jurisdictions that have pursued this restructuring - often described as "deregulation"- these policies are seen as encouraging static efficiency, ensuring that power is provided by low cost facilities.

The persistent concern, however, is that deregulated markets do not provide sufficient incentive to encourage new power sources. Jurisdictions have turned to several methods of supplementing power provider's revenues from power auctions, such as capacity markets, long-term power purchase agreements, and specific credits for favoured sources such as natural gas and nuclear power. ${ }^{12}$ If competitive markets are having difficulty motivating construction of conventional energy sources, how can they be expected to encourage an entirely revamped market driven by renewable power?

In more recent years, the growing profile of the energy industry and increased focus on climate change have encouraged regulators at all levels of government to exert influence on energy infrastructure decisions. Increased awareness of global energy markets and the environmental consequences of energy production has created unprecedented interest in the energy system and a demand for recognition of the legitimate and varied interests of national, subnational, and local stakeholders in energy decisions.

This demand often manifests as a push for each level of government-federal, state, indigenous, and local-to have a say in decisions on energy transport. This enthusiasm has sometimes produced overlapping authorities and confused standards that have left the process for approval of energy facilities in flux..$^{13}$ For example, in the United States, the separate long-standing approval processes for interstate oil pipelines, gas pipelines, and power transmission are all currently in flux.

The federal government's long-term practice has been to leave approval of interstate oil pipelines mostly to the states - a pipeline company may build a pipeline as long as it has certificates or permits from all the states along the pipeline route..$^{14}$ But at the end of President Obama's administration, the government announced that it would consider changing this standard and declared that it would do a full federal environmental review of the Dakota Access pipeline - a reversal of the usual federal policy. That decision was reversed by the incoming Trump administration and is now being litigated in the courts. ${ }^{15}$ As a result, there is continuing uncertainty about whether the federal government will be required to approve future oil pipelines.

\footnotetext{
${ }^{12}$ Hughes v. Talen Energy Marketing, LLC, 136 S.Ct. 1288 (2016).

${ }^{13}$ Coleman 2014.

${ }^{14}$ Klass and Meinhardt 2015.

${ }^{15}$ Coleman 2017a.
} 
Similarly, the states have long had control over interstate power transmission siting. Again, in its last year, the Obama administration announced a new policy, declaring that the federal government would partner with private transmission companies that wanted to build interstate transmission to support wind power. ${ }^{16}$ The new administration has not yet suggested whether it will abide by this policy and it may, again, ultimately be decided by the courts, leaving investors uncertain about whether states or the federal government has final say on new transmission projects.

Finally, interstate natural gas pipelines, unlike oil and power transport, have long been regulated by the federal government. ${ }^{17}$ But opposition to fracking has made U.S. states increasingly frustrated with their inability to stop pipeline projects that would cross their borders. New York may have hit upon an innovative solution-denying a local Clean Water Act permit to a pipeline that had already been approved by the U.S. Federal Energy Regulatory Commission. That decision, too, is being challenged in court.

Even when it is clear who the appropriate regulator is, new environmental review standards and methods have created deep uncertainty about when energy projects will be approved. The success of environmental groups in delaying the Keystone XL project, a proposed pipeline that would carry oil from the Canadian oil sands to Steele City, Nebraska, has made it a model for environmental movements around the world, who are increasingly challenging energy transport projects across the fossil fuel supply chain: gas pipelines, port facilities, liquefied natural gas projects, and power transmission..$^{18}$

But it remains unclear what rule the Keystone XL precedent stands for. Keystone XL was initially proposed in 2008 and the seven-year environmental review of the project focused on how it would affect oil production in Canada: President Obama said that if it increased oil production in Canada, he would deny it.

This focus was surprising for several reasons. First, the long-standing policy of the United States had been not to consider foreign impacts that were properly under the control of authorities in another country. Second, even in theory, it is very hard to say what the impact of a single pipeline facility will be on interstate energy markets. Third, the implied standard that energy projects should be denied if they will help an industry in a U.S. energy trading partners is, to say the least, diplomatically awkward. Fourth, the Keystone XL standard seems to be in direct conflict with the usual standard for approving pipelines, which is that they should be approved only if they would connect new sources of supply and demand. Even more confusing,

\footnotetext{
${ }^{16}$ Klass and Rossi 2017.

${ }^{17}$ Klass and Meinhardt 2015.

${ }^{18}$ Coleman 2017b.
} 
the Obama administration's decision on Keystone XL stated that 1) it was unlikely to have any impact on oil production in Canada, but 2) it would nevertheless be perceived as increasing oil production and so 3 ) should be denied notwithstanding the lengthy analysis that had delayed the project. ${ }^{19}$

Despite the difficulty in understanding what principal the Keystone XL precedent stands for, it is becoming increasingly important worldwide, with environmental groups pushing for what they call "a climate test" for energy transport projects. ${ }^{20}$ In the U.S., the Trump administration quickly reversed the previous administration's decision, approving the pipeline, but again, the propriety of this decision has been challenged by several anti-pipeline groups and will be resolved in court. In the meantime, Canada has adopted its own version of the Keystone-like climate test, but is struggling with some of the same questions about how such a test can be implemented.

These expanded climate assessments are, if anything, more dangerous to transportation infrastructure of lower carbon sources such as electricity and gas. After all, even if no new pipelines are built, oil can be transported through the existing infrastructure such as rail, barge, trucks, and ship. Gas and renewable power, by contrast, must have new dedicated transmission facilities. Following the Keystone XL precedent energy transport opponents have grown much more savvy about challenging this transmission projects on the basis that they will encourage energy production and consumption and all the externalities associated with that productionwater and air quality for natural gas production and land use and bird kills for wind projects.

Each of these trends have, at times, resulted in overlapping authority and shifting standards that can make investors wary of the energy transport projects, such as gas pipelines and electricity transmission, required to drive a transition to a low-carbon economy. This kind of regulatory uncertainty is particularly dangerous to energy transport projects because they are capital intensive-most of their costs are up front and they only pay off over time - which makes them particularly vulnerable to regulatory uncertainty. ${ }^{21}$

\footnotetext{
${ }^{19}$ U.S. Department of State 2015.

${ }^{20}$ Coleman 2017b.

${ }^{21}$ Teisberg 1993; Yang et al. 2004.
} 


\section{Principles Towards Encouraging Investment in the Energy Future}

There has never been more need for energy investment but investors have never faced such uncertainty about whether their investments will pay off. If policymakers could lessen this uncertainty, they could lower the economic cost of meeting their goals for encouraging an energy transition. How can policymakers increase certainty while respecting the legitimate concerns of stakeholders that are intensely interested in regulatory approvals?

\subsection{Principle 1: Wide Participation, One Decision-Maker}

Governments must accommodate increased interest in energy projects. Stakeholder interest in the global energy industry, both within and beyond their jurisdiction, is entirely appropriate because carbon emissions from the energy industry affect all parts of the globe. Consumer interest in energy supply chains is here to stay and local, subnational, and national politicians will naturally be interested in what the industry does beyond their borders. To that end, governments should make increased provision for wide participation in approvals of energy infrastructure, including facilitating input from all levels of government.

At the same time, ultimate decision-making authority on energy projects should, to the extent possible, be centralized. It is natural that policymakers frustrated at one level of government should seek to relitigate the issue at another level. But overlapping decision-makers is a recipe for uncertainty and there is no a priori reason to think that subjecting each proposed project to multiple veto gates would improve the overall economic and environmental result. Multiple veto gates just mean more opportunities to kill proposed investments - and that is true whether those investments are in oil, in gas, or in renewable power. So long as we believe more energy investment is necessary, we should have a unified decision-making structure that allows such investments.

Similarly, energy transport projects should not be used as opportunities to relitigate disputes about energy production that is decided by another governmental entity. If the energy transport project presents issues that are intimately connected with approval of energy production, then perhaps the two issues can be decided in a single procedure. But the transport decision should not be used after the fact with the goal of hampering a decision that has already been made about production.

Canada's traditional system of energy regulation may be a helpful model here. Canada has traditionally left issue of energy production (and, to an extent, local 
pollution) to each province's sole authority. Interprovincial issues, by contrast, are for the federal government to decide; provinces have input, but cannot veto interprovincial projects. This overall system, sometimes known as "water-tight compartments" allows for wide participation in energy decision-making but ensures that each issue is ultimately decided by a single responsible government. ${ }^{22}$

\subsection{Principle 2: Prospective Rulemaking for Environmental Reviews}

To the extent possible, changes to the rules of environmental assessment and the standards for approval should be implemented only prospectively, so that the goalposts are not moved half-way through the review process. This would allow continued improvement in environmental assessment while providing a measure of certainty to investors in interstate energy transport.

For example, scientists continue to improve techniques for assessing the "life cycle" impacts of energy production - showing the net impact of a fuel over the full cycle from production to transport to consumption. These techniques, however, do not yet provide resolution to determine the impact of any single energy project. (And may never be able to provide this resolution.) Governments should continue attempting to improve this method of environmental assessment but should not impose it as part of existing reviews. Developing experimental methods of study within an environmental review process simply imposes too much delay and uncertainty on the environmental review process.

\section{Enabling the Energy Future}

The next decades will be crucial for answering the twin challenges of global energy policy: massively expanding energy access to support increased living standards across the world while, at the same time, transitioning to forms of energy that have less impact on the air, water, and the climate. Meeting these challenges will require an unprecedented build out of long-lived energy infrastructure: new zero carbon power generators, transmission to carry renewable power to market, and pipelines, storage and liquefaction facilities for natural gas to support that transition. Society will bear the cost of these investments, and this cost will be far smaller if investors

22 Lucas 2007. 
can be sure that stable policies will ensure that they can recover their investment over many, many years. And these investments must not be delayed given the intergenerational cost of delay in moving to a new, low-carbon energy system. Thus, it has never been more crucial to find ways to accommodate increased interest and public participation in energy transport decisions without introducing uncertainty into the investment process.

\section{Bibliography}

Hughes v. Talen Energy Marketing, LLC, 136 S.Ct. 1288 (2016).

International Energy Agency, World Energy Investment Outlook (2014).

James W. Coleman, Beyond the Pipeline Wars: Reforming Environmental Assessment of Energy Transport Infrastructure, 2017 UTAH LAW REVIEW __ (forthcoming 2017)

James W. Coleman, Investing in the Shadow of the Law: How Agencies Are Using Proposed Rules to Transform Industry Long Before Final Rules Are Tested in Court, 24 GEORGE MASON LAW REVIEW 497 (2017).

James W. Coleman, Importing Energy, Exporting Regulation, 83 FORDHAM L. REV. 1357 (2014).

James W. Coleman, Importing Energy, Exporting Regulation, 38 HARVARD ENVTL. L. REV. 87 (2014).

Alexandra B. Klass \& Danielle Meinhardt, Transporting Oil and Gas: U.S. Infrastructure Challenges, 100 IOWA L. REV. 947 (2015)

Alexandra B. Klass \& Jim Rossi, Reconstituting Federalism Battles in Energy Transportation, 41 HARVARD ENVIRONMENTAL LAW REVIEW __ (forthcoming 2017).

Alastair R. Lucas, Mythology, Fantasy and Federalism: Canadian Climate Change Policy and Law, 20 PaC. MCGeorge Global Bus. \& DeV. L.J. 41 (2007).

Fabien Roques, Celine Hiroux, \& Marcelo Saguan, Optimal wind power deployment in EuropeA portfolio approach, 38 Energy Policy 3245 (2010)

Edward Rubin, Chao Chen, \& Anand Rao, Cost and performance of fossil fuel power plants with CO2 capture and storage, 35 ENERGY POLICY 4444 (2007)

Fereidoon P. Sioshansi \& W. Pfaffenberger, Electricity Market Reform: An International Perspective (2006).

Elizabeth Olmsted Teisberg, Capital Investment Strategies under Uncertain Regulation, 24 RAND J.ECON. 591 (1993).

U.S. Department of Energy, Natural Gas Infrastructure Implications of Increased Demand from the Electric Power Sector (2015).

United States Department of State, Record of Decision and National Interest Determination (Nov. $3,2015)$

U.S. Energy Information Administration, Today in Energy: Southern California natural gas inventories nearly flat this injection season, Aug. 9 2016, https://www.eia.gov/todayinenergy/detail.php?id=27432.

U.S. North American Electric Reliability Corporation, Potential Reliability Impacts of EPA's Proposed Clean Power Plan: Initial Reliability Review (2014).

Georg Woite, Capital Investment Costs of Nuclear Power Plants, International Atomic Energy Agency Bulletin (1978).

Biao Yang, Neil D. Burns, \& Chris J. Backhouse, Management of uncertainty through postponement, 42 INT'L J. PROD. RES. 1049 (2004). 